\title{
ASSESSMENT OF Hydrologic Transient Storage of THREE STREAMS
}

\author{
MiCHAEL N. GOOSEFF \\ DEPARTMENT OF AQUATIC, WATERSHED, \& EARTH RESOURCES \\ UTAH STATE UNIVERSITY $\downarrow$ LOGAN
}

Stream sediments are important locations of biogeochemical transformations upon which many stream ecosystem functions depend. Stream water is often exchanged between the stream channel and surrounding subsurface locations - this process is known as hyporheic exchange. While stream water is moving through the hyporheic zone, solutes and nutrients may undergo important chemical reactions that are not possible in the main stream channel. Further, because the hyporheic zone is composed of porous media (sand, sediment, alluvium, etc.), flow inherently slows down and the exchanging water has ample opportunity to interact with mineral grain surfaces and biofilms.

In coordination with two stream ecologists working in the area (Dr. R. O. Hall, U. Wyoming and Dr. J. L. Tank, Univ. of Notre Dame) we planned to assess the hydrologic transient storage of three streams in which Drs. Hall and Tank were studying specific stream ecosystem nitrogen cycling. The protocols that the stream ecosystem study research team was using did not explicitly call for detailed hyporheic investigations. Thus, our work was designed to complement theirs. We completed 1) topographic surveys of stream channels and water surfaces, and 2) rhodamine WT dye releases (nontoxic environmental tracing dye) in three streams. Topographic surveys allow us to characterize differences in stream geomorphology and tracing of dye releases at downstream locations allows us to characterize the extent of hyporheic exchange in each stream reach. Each stream was within a different land use: Giltner Stream was surrounded by predominantly agriculture, Jackson Hole Golf Stream ran through an urban golf course, and Ditch Creek was a pristine stream flowing through the eastern part of Grand Teton National Park. We hypothesized that each stream would have sufficiently different structure and substrate such that there would be observable differences in the hyporheic exchange characteristics of each stream.

\section{$\uparrow \quad$ RESULTS}

From our stream survey data, we calculated sinuosity (ratio of straight line distance to length of stream between two points) and the normalized longitudinal variability of the bed profile, $v$ (area of bed profile compared to best fit straight line through the profile). Stream survey data suggest that the urban golf course stream is perhaps the least complex, from a geomorphic perspective, with little sinuosity and little stream slope variability. Agricultural Giltner Stream had the highest sinuosity, but the lowest longitudinal variability, and pristine Ditch Creek had the highest longitudinal variability, and fairly high sinuosity (Table 1).

$\begin{aligned} & \text { Table 1. Summary geomorphic characteristics of the three streams } \\
& \text { studied in July, 2003. }\end{aligned}$
\begin{tabular}{lccc} 
Stream & Surveyed Length (m) & Sinuosity & 1 (m) \\
\hline Urban & 891 & .02 & 0.07 \\
\hline Agricultural & 462 & 1.50 & 0.06 \\
\hline Pristine & 258 & 1.39 & 0.20 \\
\hline
\end{tabular}


Stream tracer experiments were conducted at each of the three experimental reaches. At Giltner Stream on July 10, 2003 (on Snake River Ranch property), we conducted our first stream tracer experiment, discharge was approximately $240 \mathrm{~L} / \mathrm{s}$. The Ditch Creek stream tracer experiment was conducted on July 16, 2003, and discharge was approximately $60 \mathrm{~L} / \mathrm{s}$. The golf course stream tracer experiment was conduced on July 19, 2003, and discharge fluctuated from $80 \mathrm{~L} / \mathrm{s}$ to $110 \mathrm{~L} / \mathrm{s}$.

Resulting breakthrough curves from each of these experiments (Figure 1) suggests that there are significant differences among the reaches. The latetime tailing of the concentration data indicates longer residence time within the reach and therefore slower velocities through the reach. The urban stream has the lowest potential for hyporheic exchange and the fastest total transport of tracer. Pristine Ditch Creek has the greatest retention of tracer, indicating extensive hyporheic exchange (comparatively). Agricultural Giltner Stream is intermediate with some tracer arriving at the sampling location at 6 times the advective travel time.

These results suggest that there is ample opportunity to discern relative "retentiveness" of streams with respect to hyporheic exchange. We will continue to work with Drs. Hall and Tank in an effort to further complement our work with theirs.

We gratefully acknowledge the support of the AMK ranch during our field campaign in July 2003.

Figure 1. Rhodamine WT dye breakthrough curves from streams in three contrasting land uses. The $\mathrm{x}$-axis represents time (t) relative to the time of advection (tadv), the time at which the peak tracer concentration occurred.

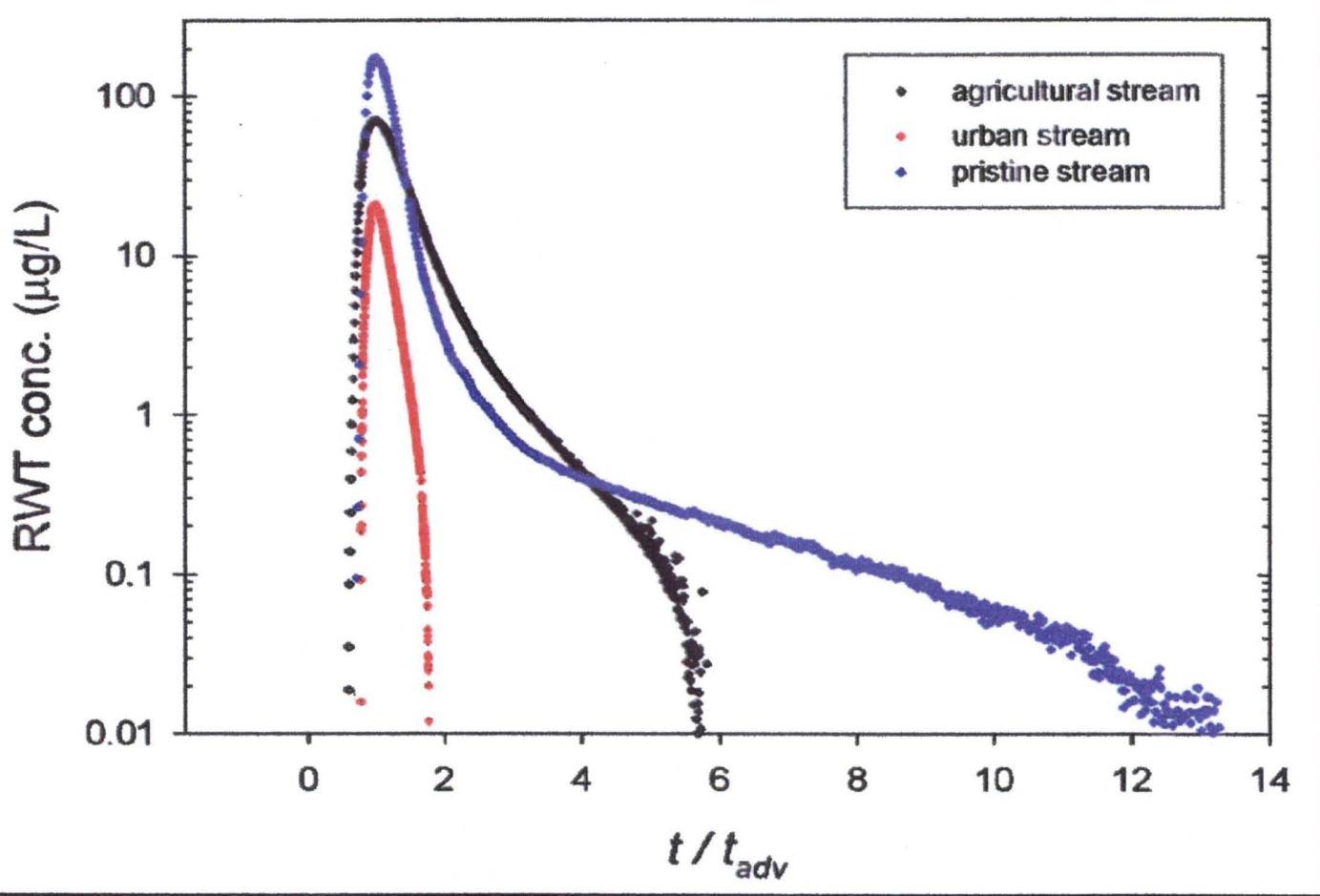

